\title{
Basal Ganglia and the Error Monitoring and Processing System: How Alcohol Modulates the Error Monitoring and Processing Capacity of the Basal Ganglia
}

\author{
M.O. Welcome and V.A. Pereverzev \\ Additional information is available at the end of the chapter
}

http://dx.doi.org/10.5772/53945

\section{Introduction}

The Basal ganglia as a subcortical relay station at the base of the forebrain is largely involved in processing of information, cognition, and movement (Gehring et al. 1993; Mathalon et al., 2003; Nick et al., 2003). Over the last century, knowledge about the basal ganglia has been acquired mainly from animal research, and pathologies that affect the basal ganglia in humans. In pathologies such as Parkinson's and Huntington's' diseases the basal ganglia's functions are greatly affected (Beste et al., 2009; Holroyd et al., 2002).

Apart from brain pathologies, psychotic substances can affect the normal functioning of the basal ganglia (Goldstein et al., 2007). Alcohol is one of the psychotic substances that affect the functions of the basal ganglia (Goldstein et al., 2007; Holroyd \& Yeung 2003; Goodlett \& Horn 2001).

Many substances that cross the blood brain barrier can affect the normal functioning of the basal ganglia either indirectly or directly (Buhler et al., 1983). The direct effect occurs, if the substances reach the basal nuclei. The indirect effect happens when pathways linking other brain regions (sub-cortical pathways) are affected. In addition, the metabolic products of these substances can exert their effect on the neurons of the basal ganglia or on the pathways linking the basal ganglia (Buhler et al., 1983; Deitrich et al 2006; Salvador \& Alfredo 2010).

In recent years, the basal ganglia have been implicated in error commission (Holroyd \& Yeung 2003). In fact, in pathologies involving the basal ganglia, research has shown that error commission rate is significantly higher, compared to controls (Holroyd et al., 2002). 
In this chapter, we examined the effect of alcohol on the functions (precisely the error monitoring and processing capacity) of the basal ganglia.

\section{Materials and methods}

Literatures for this study were searched in Pubmed, DOAJ, Embase, Google scholar, African Online Journals, and Scopus. The following keywords were used in the search processes: Alcohol and error detection; Alcohol and correction; Alcohol and error commission; Alcohol and error processing (OR monitoring); error monitoring and processing system; basal ganglia; error and the basal ganglia; alcohol and the basal ganglia. For details on the study materials and methods, see Welcome et al., 2010. In addition, we analyzed our recent data as regards to error commission dynamics in alcohol users and non-alcohol users. Data from our recent publications regarding error commission and effectiveness of cognitive functions in alcohol users and non-alcohol users were also examined.

\section{Basal ganglia and the error monitoring and processing system}

The error monitoring and processing system (EMPS) located in the substantia nigra of the midbrain, basal ganglia and cortex of the forebrain, plays a leading role in error detection and correction. Although, it is widely known that the main components of EMPS are the dopaminergic system and anterior cingulate cortex, it appears that the basal ganglia also play a crucial role (Welcome et al., 2010).

Recent data suggest that error commission is tightly monitored by the basal ganglia, and this anatomical structure remains an integral aspect of cognitive processing (Beste et al., 2009; Holroyd \& Coles 2002). Importantly, an increase in error commission is associated with decrease in cognitive functions (Welcome et al., 2010, 2011). The basal ganglia are adequately engaged with other brain areas and monitors error detection and correction (Carter et al., 1999; Garavan et al., 2002; Holroyd \& Yeung 2003). The functions of the EMPS are dependent on the degree of phasic dopamine activity on the brain areas that process and monitor error commission (Holroyd \& Yeung 2003). Other neuromediators (GABA, glycine) might also play crucial role (Wick et al., 1998).

\subsection{Error commission: Different types, one source}

Daily performances of humans are in most cases evaluated based on the outcome of activities executed. The activity function is a measure of accuracy of performance (i.e. speed of performance and the number of incorrect/correct tasks done). While the speed of tasks might be controversial in some cases, error commission rate remains a useful parameter in performance evaluation. For instance, in basal ganglia pathologies, error commission has been found to significantly increase, whereas speed of task decreases. On the contrary, even though error commission might increase in alcohol users, our data and those of other authors show faster performance of tasks in this group of people (Welcome et al., 2010; Schulte et al., 2001). 
The results of our research further stipulate that a normal physiological error commission rate by humans who do not use alcohol is approximately $5 \%$, whereas the rate for alcohol users significantly exceeds $10 \%$ (Welcome et al., 2010). This is because the brain processing of information has an automatic component, which means a basal level of error commission for a normal physiological state. Lower error commission points to more effective processing in those brain regions responsible for correct responses. Correct responses tightly engaged a network comprising the left lateral prefrontal cortex, left postcentral gyrus/inferior parietal lobule, striatum, and left cerebellum (Garavan et al., 2002; MarcoPallarés et al., 2008; Endrass et al., 2012).

The evolution of error processing is a complex one. In comparative evolutionary studies, there are evidences that suggest intrinsic error processes not only at the organismal level, but also at the cellular and subcellular level (cellular and genetic errors) (Schulte et al., 2001; Ochoa 2006; Takeuchi et al., 2005; Cohen \& Ellwein 1991). Increased error commission seen in the real world (organismal level of error commission) is the result of error processing disorder at the neuronal level (Holroyd \& Coles 2002). It is important to note that many catastrophic cases (in aviation, for instance) are caused by error commission - a failure in the brain's error monitoring and processing function or the so-called "human factor". Further study in this aspect will be of great importance to enhance safety and increase effectiveness of mental performance, especially for the necessary contingents of people such as pilots.

There are different types of errors, but almost all types have one source - the EMPS. In experimental conditions, errors are made when subject press the incorrect button on a keyboard (for example, in a Go/No-Go task) or did not pick the correct answer, or adhere strictly to instructions (Stevens et al., 2009). These errors are further classified by some authors as memory commission/omission errors; brain errors; cognitive errors etc. - all from one source - the EMPS (Giesbrecht et al., 2007; Hurst 2008; Stevens et al., 2009). Error of omission occurs as a failure to respond to tasks. The electrophysiological bases of these two types of errors are outlined in a recent work by Krigolson \& Holroyd (2007). Errors committed in the medical setting (by medics) have been referred to as medical errors which are cognitive errors of omission or commission (for review see Hurst 2008).

Another important question that comes into mind is - how do we know an error is made? Firstly, in an experimental condition, a deviation from the set goals will be decoded as error. However, in certain cases, even the participants recognize the fact that they committed error. So how does this happen? A search for the answer to this question is rooted in the less researched Pe component following ERN (Pe component is briefly discussed below). Research suggests that behavioral adjustment might represent a useful in error awareness. There evidences suggest a close relationship among error commission, behavioral adjustment and executive functions (Garavan et al., 2002; Marco-Pallarés et al., 2008). The awareness of errors might be the result of close engagement between executive functions and the brain EMPS. Hence, it is probable that when executive functions (e.g. attention) are closely engaged with the EMPS, error awareness increases. Furthermore, recent evidence shows the capacity of the basal ganglia (through the basal ganglia-cortical pathways) to implement successful performances that were initially produced by other brain regions, 
indicating precise functional connections between basal ganglia circuits and the motor regions that directly control performance (Charlesworth et al., 2012). Also, the basal ganglia generate a variety of behaviors during execution of task and learn to implement the successful behaviors in their repertoire to meet the target (Sur \& Schultz 1999).

In electrophysiological studies, error commission is reflected in the reduced amplitude of the Error Related Negativity, ERN (or Error Negativity, Ne) (Falkenstein et al., 2000; Ridderinkhof et al., 2002), a negative deflection in the electroencephalogram with a maximum in the midline of the frontocentral region of the scalp having a latent period around 50-150ms (Falkenstein et al., 2000; Ridderinkhof et al., 2002).

The ERN amplitude might show gradual decrease for older adults (Pontifex et al., 2010). However, because of amplitude difference across different age groups caused by gradual increase in brain regions involved in error processing, the number of brain regions responsible for error processing and monitoring may vary according to the age of the subjects under analysis. Importantly, not only maturation of the neural systems that identifies different errors account for this increase (Stevens et al., 2009), but also neural plasticity. ERN is smaller for adolescents (Pontifex et al., 2010).

Nowadays, a growing body of data suggests that error commission is associated not only with the early time-course ERN components of the electroencephalogram but also with a successive neurophysiological late error positivity $(\mathrm{Pe})$ following motor execution. The exact cognitive and physiological processes contributing to these two components, as well as their functional independence, are still not fully been unraveled (Vocat et al., 2008). The occurrences of ERN and Pe involve activation of a distinct configuration of intracranial generators during error commission. Pe peaks approximately at approximately $300 \mathrm{~ms}$ after erroneous actions (Vocat et al., 2008; Endrass et al., 2012).

For about two decades the Pe component has remained elusive and has become the subject of a fierce debate in the scientific community (Falkenstein et al., 2000; Vocat et al., 2008; Dhar M et al., 2011).

Several studies have suggested that the error positivity (Pe) reflect conscious error awareness (Dhar et al. 2011; Garavan et al., 2002; Marco-Pallarés et al., 2008). Although, previous studies have disputed this view. According to Falkenstein et al. (2000) the Pe, represent a error-specific component, which is independent of the ERN, and hence is associated with a later aspect of error processing or post-error processing. Falkenstein and coauthors (2000) further argue that the Pe reflects conscious error processing or the posterror adjustment of response strategies.

A recent report further supports the error awareness property of the Pe component. Endrass and colleagues (2012) have recently shown that error awareness mainly influences the Pe, whereas the ERN seems unaffected by conscious awareness of an error. This confirms that the Pe is related to error commission. Hence this component is sensitive to the salience of an error and that salience secondarily may trigger error awareness (for review see Endrass et al., 2012). 
For review on ERN and Pe amplitude see Amodio et al. (2006), Endrass et al. (2012), Pontifex et al. (2010), Falkenstein et al. (2000).

\subsection{Error commission in controls, and Basal ganglia pathologies}

Because both ERN and Pe show promise for use in clinical setting for the diagnosis of psychopathology (including basal ganglia pathologies), further research on these components is necessary. To this end, reports clearly indicate that these error components may represent a predisposition factor for behavioral disorders including substance use disorders (alcoholism), brain (basal ganglia) pathologies (Olvet \& Hajcak 2008; Franken et al., 2010; Fein \& Chang 2008; Van Veen \& Carter 2006; Aarts \& Pourtois 2010). Although, there are controversies on whether or not the ERN actually has a diagnostic significance. Studies have suggested that the ERN reflect a trait, and not a state factor (Pailing \& Segalowitz 2004; Olvet \& Hajcak 2008). For a better appreciation of the usefulness of ERN and Pe in psychopathology (including basal ganglia dysfunctions) a mathematical modeling involving the second derivative of these components and segmental analysis might be necessary which will give a glimpse into their importance for clinical diagnosis.

Besides alcohol and basal ganglia pathologies, sleep deprivation (or insomnia) is also a factor for increase in error commission which might result in various catastrophes including industrial and engineering disasters, motor accidents etc. (Mitler et al., 1988). This suggests the presence of a circadian control mechanism in EMPS.

Vocat et al. (2008) found that the ERN correlates with the level of state anxiety, even in the subclinical range, whereas the Pe correlates negatively with the total number of errors and positively with the improvement of response speed on correct trials.

The mechanism of increase in error commission in people with basal ganglia dysfunction is a complex one. A growing body of literature data suggests the involvement of attention control mechanisms. For instance, patients with Huntington's disease show great decrease in the ability to assess various aspects of tasks (disorder in attention), resulting from a disorder in action-selection processes. This obviously will lead to increase in error commission in tasks (Beste et al., 2008). One recent study by Bocquillon and co-workers (2012) suggests that basal ganglia pathologies results in resistance impairment to distracters (which might actually, in most cases represent competing neural information), hence providing more grounds for error commission. An electromagnetic tomography and electrophysiological study involving the P300 found that, unlike in the controls, in patients with Parkinson's disease, disruption of the frontoparietal network impaired resistance to distracters, which resulted in attention disorders (Bocquillon et al., 2012). However, increase in error commission may in part be the result of global cognitive impairment and inhibitory control disorders (Gauggel et al., 2004).

In another study, Beste et al. (2006) assessed ERN amplitude in a speeded reaction task under consideration of the underlying genetic abnormalities in patients with Huntington's disease. The findings of the researchers showed a specific reduction in the ERN, suggesting impaired error processing. Furthermore, the ERN was closely related to the trinucleotide 
CAG-repeat expansion. The authors concluded that the reduction of the ERN is likely to be an effect of the dopaminergic pathology. And that the ERN might be a measure for the integrity of striatal dopaminergic output function (Beste et al., 2006). This view is in direct agreement with previous studies on the role of the dopaminergic system in error commission (Holroyd \& Yeung 2003). In contrary to the study of Beste and colleagues (2006), previous study by Holroyd and colleagues (2002) did not find any difference in ERN amplitude between patients with basal ganglia pathology (precisely Parkinson disease) and the controls. Although the authors noted that the error-processing system associated with the ERN was not severely compromised in the patient population that participated in the study.

Patients with basal ganglia pathologies have slower reaction time compared to controls (Berry et al., 1999). It appears that time processing disorders might even be a more useful factor to assess basal ganglia pathologies (Beste et al., 2007). In a time-estimation and timediscrimination task Beste et al. (2007) found deterioration of time-estimation processes in symptomatic and even presymptomatic Huntington's disease. However, timediscrimination processes were not affected. Time processing is a critical function of the cortico-basal ganglia circuits (Jin et al., 2009). Although previous report has disputed the involvement of the basal ganglia in timing (Aparicio et al., 2005). A general probation of the components of error processing in various cultural groups, while controlling for factors such as age, gender, educational level, various mental states, and psychopathologies is necessary.

\section{Pathways of alcohol's action on the error monitoring and processing capacity of the Basal ganglia}

For the first time in 2002, it was reported that alcohol consumption disrupts error monitoring (Ridderinkhof et al., 2002). According to electro-physiological studies, the effect of alcohol on the Error Monitoring and Processing System, EMPS is reflected in the reduced amplitude of the Error Related Negativity (ERN) (Falkenstein et al., 1995; Ridderinkhof et al., 2002), a negative deflection in the electroencephalogram with a maximum in the midline of the frontocentral region of the scalp having a latent period around 50-150ms (Easdon et al., 2005; Ridderinkhof et al., 2002; Welcome et al., 2010).

Even though the effect of alcohol on EMPS is documented, information on how alcohol affects error monitoring and processing is scanty (i.e. the mechanism of alcohol's effect on EMPS remain adequately researched). Two co-researchers, Holroyd and Yeung in 2003 in their review suggested that alcohol's effect on error monitoring and processing is likely indirect, not direct, and that the mechanisms remained unknown. They however suggested that alcohol might modulate EMPS through its effect on the dopamine system. Recently, in our review we suggested indirect mechanisms by which alcohol disrupts the EMPS (Welcome et al., 2010). However, based on increasing evidences (Deitrich et al., 2006; Wick et al., 1998; Quertemont 2004; Buhler et al., 1983), a direct disruption might also be possible, especially, if we consider the possibility that receptors of neuromediators might have "alcohol pockets-receptors". It is reported that glycine and GABAA receptors may harbor specific pockets for alcohol (Wick et al., 1998). 


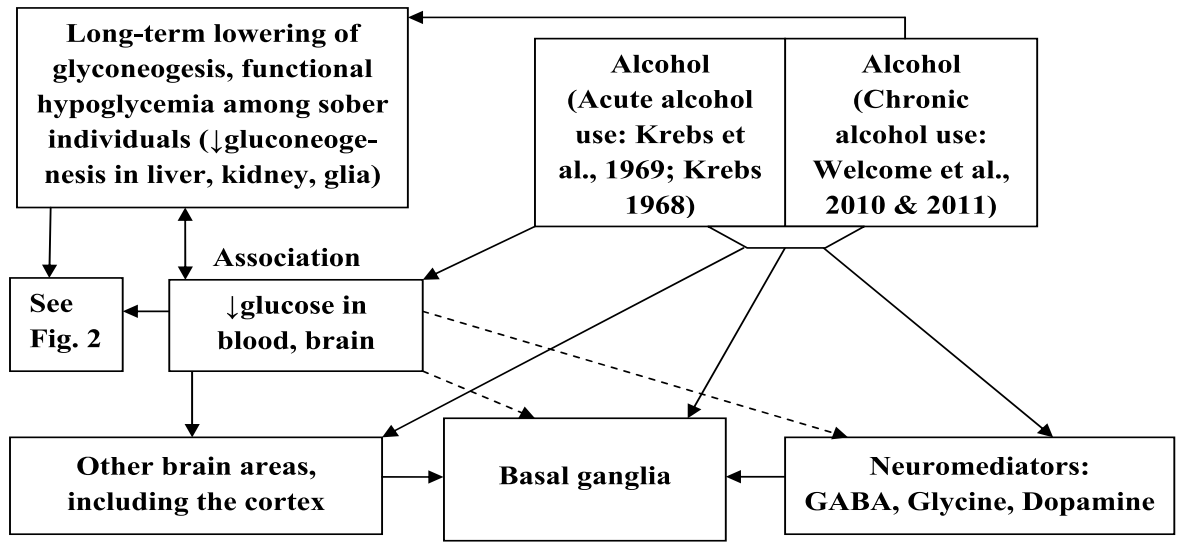

Figure 1. Pathways of alcohol's action on the Basal Ganglia

Besides, it is known that alcohol readily crosses the blood brain barrier. In the brain, alcohol can disrupt the transmission of signals through the basal ganglia/or the processing of information by the basal ganglia. The following scenarios are possible (see fig. 1):

a. Direct effect of alcohol on the processing capacity of the basal ganglia by inhibiting cellular processes, depending on the dose of alcohol;

b. Indirect effect of alcohol on the processing capacity of the basal ganglia by affecting other brain areas connected to the basal ganglia;

c. Direct effect on neuromediators that modulate the processing of information in the basal ganglia and/or associated brain pathways;

d. Action of alcohol metabolites (acetaldehyde; acetate; protein, lipid, enzyme \& DNA adducts of alcohol) on the processing of information in the basal ganglia and/or associated brain pathways. The brain might contain alcohol metabolizing enzymes such as ADH-1, ADH-2, ADH-3 (might play little or no role), CYP P4502E1 (Quertemont 2004; Buhler et al., 1983), although there might be a huge genetic variance. It important to note that injection of acetate into the brain causes significant decrease in motor function (Deitrich et al., 2006).

\section{Theories suggesting alcohol's effect on the error monitoring and processing capacity of the Basal ganglia}

There are at least five hypotheses \& theories that might explain how alcohol use affects the error monitoring and processing capacity of the basal ganglia. They are hypotheses of error detection; reinforcement-learning theory; conflict-monitoring theory; the integrated conflict monitoring-reinforcement learning theory; and hypothesis of alcohol-related glucosedependent system of error monitoring \& processing (Holroyd \& Coles 2002; Holroyd \& 
Yeung 2003; Welcome et al., 2010). Of these theories/hypotheses, only the reinforcementlearning theory; conflict-monitoring theory; and the integrated conflict monitoringreinforcement learning theory is close to defining the role of basal ganglia in the EMPS. The hypothesis of alcohol-related glucose-dependent system of error monitoring \& processing (ARGD-EMPS Hypothesis) suggests a mechanism of alcohol's effect on the EMPS (Welcome et al., 2010).

\subsection{The reinforcement learning theory}

One of the integral properties of the basal ganglia is to determine whether the end-result of events will be favorable or not; and is crucial to the functioning of EMPS. The basal ganglia monitor and steadily predict the result of ongoing events (Welcome et al., 2010; Botvinick et al., 2001 \& 2004; Holroyd \& Yeung 2003; Garavan et al., 2002; Gehring et al., 1993 \& 2001). The basal ganglia is one of the many brain structures that send command information to the ACC for further processing (it is presently not clear the kind of information that might require further processing in ACC, or whether these processes only represent one of the many brain mechanisms for safety) (Holroyd \& Coles 2002; Holroyd \& Yeung 2003; Welcome et al., 2010). It is however, possible that these command information are too complex for only the basal ganglia to process, hence need other more specialized locations. That is why the ACC functions as a selector for conflicted command. This is why the ACC is regarded as a control filter (Welcome et al., 2010; Carter et al., 1998; Nieuwenhuis et al., 2003; Ridderinkhof et al., 2003). The major neuromediator here is dopamine. Its tonic activity depends on reinforcing properties of alcohol (Holroyd \& Yeung 2003; Munte et al., 2008; Montague et al., 1996). Alcohol may increase the tonic activity of dopamine system and subsequently leading to inhibition of neuronal activity, the result is increased error commission (Welcome et al., 2010; Holroyd \& Yeung 2003; Easdon et al., 2005).

\subsection{The conflict-monitoring theory}

Although there are less information as regards to this theory with respect to the basal ganglia. Research suggests that the basal ganglia may be actively engaged with other systems to monitor conflict (through the sub-cortical pathways). This is an important aspect of information processing for cognitive control (Botvinick et al., 2001 \& 2004; Welcome et al., 2010; Gehring et al., 2001). Conflict occurs as a result of simultaneous activation of different regions, controlling the activation of different levels of competing motor control units in the motor cortex. Processing of stimulus is characterized by constant flow of activity in the pathways that send stimulus related information to the cortex of the hindbrain, and subsequently results in the corresponding response in the motor cortex (Botvinick et al., 2001 \& 2004; Welcome et al., 2010). Distractive stimulus may activate incorrect response in this system (Goldstein et al., 2007; Holroyd \& Coles 2002). Alcohol related disruption of information processing decreases the activation of correct responses (through its inhibitory effect) (Holroyd \& Yeung 2003). In addition to the dopamine system (Holroyd \& Coles 2002), GABA and glycine might also play a role (Wick et al., 1998). 


\subsection{Integrated conflict monitoring-reinforcement learning theory}

In view of this theory, although not fully clear, the basal ganglia generate error signals (i.e. the basal ganglia undertake processing of input signals, and are end-result predictors). Hence, the basal ganglia have been referred to as adaptive critics. It is also possible that the error signals processed in the basal ganglia are received from ACC (Ridderinkhof et al., 2003; Umhau et al., 2003). Sometimes, however, end-result can be different from the input signal (especially when result was not predicted). The resultant effect is a shift in dopamine signal. The error produced is called temporal difference error. These errors are sent through the dopamine system to other brain regions for further analysis: a) motor control systems (such as dorsolateral prefrontal cortex, amygdala); b) control filter (ACC); c) and again to the basal ganglia. These processes suggest that the basal ganglia are some of the "chief brain error processors" that ensure adequate completion of information processing for cognitive control. A disruption in dopamine signal caused by alcohol in these brain regions disinhibits adequate processing of information (Nieuwenhuis et al., 2003; Ridderinkhof et al., 2003; Umhau et al., 2003; Holroyd \& Yeung 2003; Holroyd \& Coles 2002; Hester et al., 2005; Garavan et al., 2002; Easdon et al., 2005).

\section{Mechanism \& processes of alcohol's effect on the error monitoring and processing functions of the Basal Ganglia: The ARGD-EMPS hypothesis revisited and redefined}

How does alcohol exert its action on the error monitoring and processing capacity of the basal ganglia? This is a question that is virtually left unanswered as the traditional theories of error processing do not provide suitable answers. Of all the theories of error monitoring and processing, only the hypothesis of alcohol-related glucose-dependent system of error monitoring \& processing (ARGD-EMPS hypothesis) gives a somewhat precise definition of how alcohol affects the EMPS, although, even ARGD-EMPS hypothesis has its shortcomings. For one reason, while ARGD-EMPS hypothesis proposes an indirect mechanism of alcohol's action on the EMPS, a direct pathway is also possible. Secondly, the hypothesis considers competency of glucose homeostasis regulation to affect the ACC primarily, and then, consequently, affecting other components of the system. Finally, the effect of alcohol on the EMPS might take a much longer time than expected.

The ARGD-EMPS hypothesis which explains the general processes and mechanisms of alcohol-related disruption of the EMPS, suggests that the disruption of EMPS by alcohol might be indirect and realized through its effect on the competency of glucose homeostasis regulation (Welcome et al., 2010) (also see Fig. 2). The major postulates of this hypothesis hold that the error processing capacity of the ACC depends on the blood-brain glucose proportionality level, which affects the dopaminergic system as a major component of the EMPS (Pizzagalli et al., 2003; Umhau et al., 2003; Goldstein et al., 2007).

From figure 2, one can notice that one of the central dogma of the ARGD-EMPS hypothesis is the degree of glucose homeostasis (allostasis is a better terminology) regulation in blood 


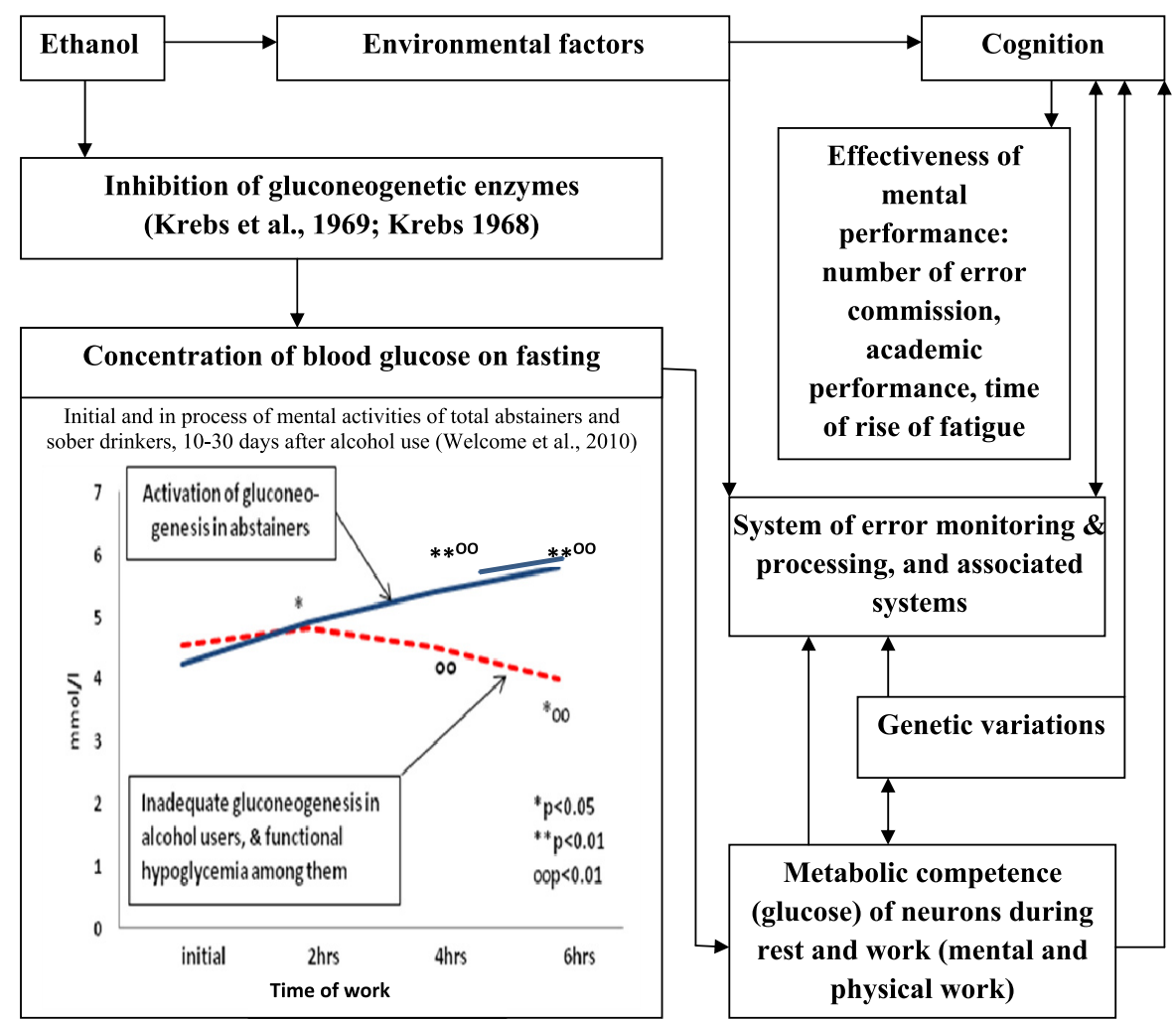

Significance level: *in relation to the initial level; ${ }^{\circ}$ in relation to the parameters of the opposite group.

References to figure: Welcome et al., 2010 \& 2011; Krebs 1968; Nieuwenhuis et al., 2004; Ridderinkhof et al., 2002; Holroyd \& Yeung 2003; Montague et al., 1996; Carter et al., 1998; Bello \& Hajnal 2006; Haltia et al., 2007; Williams et al., 2007; de Galan et al., 2006; Calhoun et al., 2004; Umhau et al., 2003; Haight \& Keatinge 1973; Krebs et al., 1969; Wick et al. 1998

Figure 2. Ethanol affects the functions of the EMPS by altering the brain and blood glucose levels through its action on the mechanisms (gluconeogentic etc) that regulate the blood-brain glucose concentration (the effect is also evident among sober individual, even for 10-30 days after alcohol use. Genetic variations in dopamine, GABA receptors can also affect the activities of the EMPS. The resultant effects of all these components on EMPS indirectly affect cognition, at the same time as the level of cognition can affect the activity level of EMPS. Ethanol as a component of environmental factors can affect cognition. Ethanol reduces the glycemic level of alcohol users, especially in tasks requiring high cognitive control, and subsequently affecting EMPS.

and brain. Disorder in glucose homeostasis regulation in blood, and in the brain, especially under long-term intensive mental activities in alcohol users is the basis for the formulation of the ARGD-EMPS hypothesis. Importantly, road traffic, and aviation catastrophes, glucose 
allostasis regulation might stand out to be a major reason. Unarguably, long-hour driving and airplane control requires significant cognitive control, judgment. In alcohol users (even after 7-30 days of alcohol use), this cognitive control might malfunction by increase in error commission, especially after long period ( $\sim 4 \mathrm{hrs}$ and above) of driving or control. The situation might be pronounced for young people. Besides, catastrophic cases of vehicle accidents involving alcohol use are more prevalent among young people, especially among students (Del Rio Carmen et al., 2001). While alcohol's time-dose effects are largely studied, data about the time-response effect in healthy young individuals remain scanty. In our recent work (Welcome et al., 2011), for the first time, we were able to identify statistically, a lowering of glycemic allostasis regulation in young sober healthy students who use alcohol episodically in moderate doses. This lowering in glycemia correlated significantly with cognitive functions. The study was conducted after one week to a month abstinence period for alcohol users to extensively study the time-response effect of alcohol.

\subsection{Relationship between alcohol use and cognitive functions}

In the study (Welcome et al., 2011; tables 1, 2, and 3), analysis of the parameters of effectiveness of active attention (a function of cognitive control) in the participants was conducted according the results of the test "Correction Probe" and was based on the number of error commission in the test. Number of error commission by the episodic alcohol users in the test "Correction Probe" was by $5.43(\mathrm{P}<0.02)-12.77(\mathrm{P}<0.005)$ times higher compared to the non-alcohol users in all phases (tests) of the experiment (table 1). Number of error commission by alcohol episodic alcohol users significantly exceeded in all phases of mental activities (after 2, 4 and $6 \mathrm{hrs)}$ ) and was after $6 \mathrm{hrs}$ from the start $+17.6 \pm 5.8$ errors $(\mathrm{P}<0.01)$, or $218.4 \%$ in relation to the initial number (table 1$)$. Among the non-alcohol users, the number of errors did not change and remained low and stable during the experiment.

The number of errors in the test "Correction Probe" also allowed to analyze a very important property of active attention - concentration which is the possibility to focus on ongoing activities so as to minimize error commission to $\leq 5$ errors in the test "Correction Probe". This property of attention was especially expressed among the non-alcohol users (in $87.5-100.0 \%$ cases), both in the initial $\left(1^{\text {st }}\right)$ test and in course (dynamics) of carrying out mental activities (table 1). Among alcohol users attention concentration or focus was retained only in 4 ( $>5$ errors in the test "Correction Probe") out of 19 persons. As a result of this, the estimated relative probability of maintaining proper attention concentration or focus ( $\leq 5$ errors in the test "Correction Probe") among non-alcohol users was 4.15 times $\left(\mathrm{P}<0.002 ; \chi^{2}=10.296\right)$ higher, than among their colleagues who use alcohol. According to the measure of carrying out mental activities, concentration of attention among the alcohol users decreased and remained low even after two hrs of rest. As a result, the risk of error commission of more than 5 in the test "Correction Probe" and lowering of the concentration of attention among the alcohol users increased from 6.29 to $8.00\left(\mathrm{P}<0.001 ; \chi^{2}=17.459\right)$ times compared to the non-alcohol users. 


\begin{tabular}{|c|c|c|c|c|}
\hline \multirow{2}{*}{$\begin{array}{l}\text { Test number and time of carrying } \\
\text { out the test }\end{array}$} & \multicolumn{2}{|c|}{ Number of errors in the test "CP" } & \multicolumn{2}{|c|}{ Dynamics of number of errors } \\
\hline & group № 1 & group № 2 & group № 1 & group № 2 \\
\hline \multirow{2}{*}{$\begin{array}{c}1 \text { st, initial }(\mathbf{M} \pm \mathbf{m}) \text {, } \\
\mathrm{P}, \mathrm{t} \text { at } \mathrm{df}=7-\text { to the parameters of } \\
\text { № } 1\end{array}$} & $2.8 \pm 0.8$ & $15.2 \pm 3.5$ & -- & -- \\
\hline & & $\mathrm{P}<0.02 ; \mathrm{t}=3.471$ & & \\
\hline \multirow{3}{*}{$\begin{array}{c}2^{\text {nd }}, \text { after } 2 \text { hrs of work }(\mathrm{M} \pm \mathrm{m}) \\
\mathrm{P}, \mathrm{t}^{*} \text { - to the initial value of its own } \\
\text { group } \\
\mathrm{P}, \mathrm{t}^{\circ} \text { at } \mathrm{df}=7 \text { - to the initial value of } \\
\text { № } 1\end{array}$} & $2.4 \pm 0.7$ & $18.2 \pm 4.1$ & $-0,4 \pm 0,5$ & $+3.0 \pm 1.4 *$ \\
\hline & $\mathrm{P}>0.05$ & $\mathrm{P}>0.05$ & $\mathrm{P}>0.05$ & $\begin{array}{c}\mathrm{P}<0.05 ; \mathrm{t}=2.143 ; \\
\mathrm{df}=18\end{array}$ \\
\hline & & $\mathrm{P}<0.01 ; \mathrm{t}=3.847$ & & $\mathrm{P}>0.05 ; \mathrm{t}=2.272$ \\
\hline \multirow{3}{*}{\begin{tabular}{|c|}
$3^{\text {rd }}$, after 4 hrs of work $(\mathrm{M} \pm \mathrm{m})$ \\
$\mathrm{P}, \mathrm{t}^{*}$ - to the initial value of its own \\
group \\
$\mathrm{P}, \mathrm{t}^{\circ}$ at $\mathrm{df}=7$ - to the value of № 1
\end{tabular}} & $3.1 \pm 0.7$ & $25.1 \pm 4.9$ & $+0.3 \pm 0.8$ & $+9.0 \pm 3.5^{*}$ \\
\hline & $\mathrm{P}>0.05$ & $\mathrm{P}>0.05$ & $P>0.05$ & $\begin{array}{c}\mathrm{P}<0.02 ; \mathrm{t}=2.586 ; \\
\mathrm{df}=17\end{array}$ \\
\hline & & $\mathrm{P}<0.005 ; \mathrm{t}=4.477$ & & $\mathrm{P}<0.05 ; \mathrm{t}=2.415$ \\
\hline \multirow{2}{*}{$\begin{array}{c}4^{\text {th }}, \text { after } 6 \text { hrs of work }(\mathrm{M} \pm \mathrm{m}) \\
\mathrm{P}, \mathrm{t}^{*} \text { - to the initial value of its own } \\
\text { group }\end{array}$} & $2.6 \pm 0.7$ & $33.2 \pm 7.1 * \odot$ & $-0.2 \pm 0.6$ & $+17.6 \pm 5.8^{* \odot 9}$ \\
\hline & $\mathrm{P}>0.05$ & $\begin{array}{c}\mathrm{P}<0.05 ; \mathrm{t}=2.288 \\
\mathrm{df}=17\end{array}$ & $\mathrm{P}>0.05$ & $\begin{array}{c}\mathrm{P}<0.01 ; \mathrm{t}=3.034 ; \\
\mathrm{df}=17\end{array}$ \\
\hline $\mathrm{P}, \mathrm{t}$ at $\mathrm{df}=7-$ to the value of № 1 & & $\mathrm{P}<0.005 ; \mathrm{t}=4.315$ & & $\mathrm{P}<0.02 ; \mathrm{t}=3.052$ \\
\hline $5^{\text {th }}$, after 2 hrs of rest $(\mathrm{M} \pm \mathrm{m})$ & $2.5 \pm 1.1$ & $23.3 \pm 4.2$ & $-0.3 \pm 0.9$ & $+13.2 \pm 6.9$ \\
\hline$P, t \&$ at $d f=7-$ to the value of № 1 & & $\mathrm{P}<0.005 ; \mathrm{t}=4.755$ & & $\mathrm{P}>0.05$ \\
\hline
\end{tabular}

Note: group № 1 -non-alcohol users (8 persons); group № 2 - alcohol users (19 persons). Significance of differences was calculated with Student's t-test: ${ }^{*}$ - significance of the differences in relation to the parameters of students in its own group on the first test (initial parameters in its own group); significance of the differences in relation to analogical parameters of non-alcohol users in the same phase (number) of testing.

Table 1. Number of errors and effectiveness of attention in the test "Correction Probe" (CP)

These facts strongly suggest that alcohol use, even episodic in moderate doses leads to longterm (1 -4 weeks) negative effect on the state of cognitive functions in sober young people. This is manifested through decrease in the concentration of attention and worsening of the processes of active attention (table 1), processes of thinking, different types of memory resulting in inability to preserve proper level of mental performance for a long period of time and relative rise of fatigue. In addition, analysis of academic performance (which might represent a factor of cognitive functions) show decrease in the effectiveness to sit for examinations only among the alcohol users.

\subsection{Episodic alcohol use, glycemia and cognitive functions: What are the possible connections?}

Research data on the chief role of glucose in energy supply for neurons and the inhibition of gluconeogenesis during acute or chronic alcohol poisoning have been repeatedly reported (Krebs 1968; Krebs et al., 1969; Goodlett \& Horn 2001). The result of our study suggests that that inhibition of gluconeogenesis by ethanol is a fairly long process ( $1-4$ weeks, and may possibly last longer until complete recovery of gluconeogenetic enzymes by de novo synthesis). 


\begin{tabular}{|c|c|c|c|}
\hline \multirow[t]{2}{*}{ Blood sampling } & \multicolumn{3}{|c|}{ Concentration of glucose in capillary blood $(\mathrm{M} \pm \mathrm{m}), \mathrm{mmol} / \mathrm{l}$} \\
\hline & All participants, $n=27$ & $\begin{array}{l}\text { Non-alcohol users, } \\
\text { group № } 1, \mathrm{n}=8\end{array}$ & $\begin{array}{l}\text { Alcohol users, } \\
\text { group № 2, n=19 }\end{array}$ \\
\hline $\begin{array}{c}\text { Initial, before work } \\
\mathrm{t} \text {, St. to abstainers } \\
\text { group №1 }\end{array}$ & $\begin{array}{c}4.45 \pm 0.12 \\
P>0.05\end{array}$ & $4.24 \pm 0.19$ & $\begin{array}{c}4.54 \pm 0.15 \\
P>0.05\end{array}$ \\
\hline $\begin{array}{c}\text { After } 2 \text { hrs of work } \\
{ }^{*} t \text {, St. to the initial } \\
t \text {,St. to № } 1 \\
\text { Dynamics to initial } \\
{ }^{*} t \text {, St. to the initial } \\
t \text {,St. to № } 1\end{array}$ & $\begin{array}{c}4.85 \pm 0.10 * \\
\mathrm{P}<0.02 ; \mathrm{t}=2.548 ; \mathrm{df}=26 \\
\mathrm{P}>0.05 \\
+0.40 \pm 0.08 * \\
\mathrm{P}<0.001 ; \mathrm{t}=5.000 ; \mathrm{df}=26 \\
\mathrm{P}<0.05 ; \mathrm{t}=2.385 ; \mathrm{df}=7\end{array}$ & $\begin{array}{c}4.91 \pm 0.15 * \\
\mathrm{P}<0.05 ; \mathrm{t}=2.792 ; \mathrm{df}=7 \\
+0.67 \pm 0.08 \text { * } \\
\mathrm{P}<0.001 ; \mathrm{t}=8.375 ; \mathrm{df}=7\end{array}$ & $\begin{array}{c}\text { 4.82 } \pm \mathbf{0 . 1 3} \\
\mathrm{P}>0.05 ; \mathrm{t}=1.914 ; \mathrm{df}=18 \\
\mathrm{P}>0.05 \\
+\mathbf{0 . 2 8} \pm \mathbf{0 . 1 0} \\
\mathrm{P}<0.02 ; \mathrm{t}=\mathbf{2 . 8 0 0} ; \mathrm{df}=18 \\
\mathrm{P}<0.02 ; \mathrm{t}=3.042 ; \mathrm{df}=7\end{array}$ \\
\hline $\begin{array}{c}\text { After 4hrs of work } \\
{ }^{*} \mathrm{t} \text {, St. to the initial } \\
\mathrm{t} \text {,St. to № } 1 \\
\text { Dynamics to initial } \\
{ }^{*} \mathrm{t} \text {, St. to the initial } \\
\mathrm{t} \text {,St. to № } 1\end{array}$ & $\begin{array}{c}4.79 \pm 0.12 \text { n=26 } \\
\mathrm{P}>0.05 ; \mathrm{t}=2.000 ; \mathrm{df}=25 \\
\mathrm{P}<0.05 ; \mathrm{t}=2.385 ; \mathrm{df}=7 \\
+0.35 \pm 0.15 \text { * } \\
\mathrm{P}<0.05 ; \mathrm{t}=2.333 ; \mathrm{df}=25 \\
\mathrm{P}<0.01 ; \mathrm{t}=3.568 ; \mathrm{df}=7\end{array}$ & $\begin{array}{c}5.40 \pm 0.18 * \\
\mathrm{P}<0.005 ; \mathrm{t}=4.462 ; \mathrm{df}=7 \\
+\mathbf{1 . 1 6} \pm \mathbf{0 . 1 7} \text { * } \\
\mathrm{P}<0.001 ; \mathrm{t}=6.824 ; \mathrm{df}=7\end{array}$ & $\begin{array}{c}4.52 \pm 0.11^{\circ} \mathrm{n}=18 \\
\mathrm{P}>0.05 ; \mathrm{t}=0.091 ; \mathrm{df}=17 \\
\mathrm{P}<0.005 ; \mathrm{t}=4.190 ; \mathrm{df}=7 \\
-\mathbf{0 . 0 1} \mathbf{0 . 1 4} \mathrm{n}=18 \\
\mathrm{P}>0.05 ; \mathrm{t}=0.007 ; \mathrm{df}=17 \\
\mathrm{P}<0.002 ; \mathrm{t}=5.294 ; \mathrm{df}=7\end{array}$ \\
\hline $\begin{array}{c}\text { After } 6 \text { hrs of work } \\
{ }^{*} \mathrm{t} \text {, St. to initial } \\
\mathrm{t} \text {,St. to № } 1 \\
\text { Dynamics to initial } \\
{ }^{*} \mathrm{t} \text {, St. to the initial } \\
\mathrm{t} \text {,St. to № } 1\end{array}$ & $\begin{array}{c}4.54 \pm 0.21^{\circ} \mathrm{n}=26 \\
\mathrm{P}>0.05 ; \mathrm{t}=0.372 ; \mathrm{df}=25 \\
\mathrm{P}<0.005 ; \mathrm{t}=5.020 ; \mathrm{df}=7 \\
+0.10 \pm 0.25 \\
\mathrm{P}>0.05 ; \mathrm{t}=0.400 ; \mathrm{df}=25 \\
\mathrm{P}<0.005 ; \mathrm{t}=4.848 ; \mathrm{df}=7\end{array}$ & $\begin{array}{c}5.78 \pm 0.13 \text { * } \\
\mathrm{P}<0.001 ; \mathrm{t}=6.696 ; \mathrm{df}=7 \\
+1.54 \pm 0.16^{*} \\
\mathrm{P}<0.001 ; \mathrm{t}=9.625 ; \mathrm{df}=7\end{array}$ & $\begin{array}{c}3.99 \pm 0.18{ }^{\circ} \mathrm{n}=18 \\
\mathrm{P}<0.05 ; \mathrm{t}=2.347 ; \mathrm{df}=17 \\
\mathrm{P}<0.001 ; \mathrm{t}=8.063 ; \mathrm{df}=7 \\
-\mathbf{0 . 5 5} \pm 0.24{ }^{*} \mathrm{n}=18 \\
\mathrm{P}<0.05 ; \mathrm{t}=2.292 ; \mathrm{df}=17 \\
\mathrm{P}<0.001 ; \mathrm{t}=7.232 ; \mathrm{df}=7\end{array}$ \\
\hline
\end{tabular}

Note: * differences are significant in relation to the initial level of glycemia in its own group before work (the first blood sampling) with respect to Student's t criterion (St.). - differences are significant in relation to the level of glycemia among the non-alcohol users on the same phase of blood sampling. $n$-number of participants in the group.

Table 2. Initial parameters and dynamics of blood glucose in capillary blood of all respondents in a condition of long-term, intensive mental activities

Inadequate level of glycemia for long-term energy supply for actively working neurons, which is accompanied by lowering of their activities and subsequently a decline in cognitive function, even in sober respondents could be due to inadequacy in the activity of gluconeogenetic enzymes. The observed disorders in glucose metabolism may be expressed in conditions of intense functional workloads, for example, mental activities, imposed on sober respondents on fasting in the catabolic phase of metabolism. This assumption is confirmed by the result of studying the dynamics of glucose in the blood of hungry people with different attitudes to alcohol in a condition of long-term functional workload (on fasting) in the form of intensive 6 hrs mental activities (table 2).

The results of this study showed increase in the level of blood glucose in all 27 participants in the first 2 hrs of mental activities (figure 2; table 2) by $+0.40 \mathrm{mmol} / \mathrm{l}(\mathrm{P}<0.001)$ : among the non-alcohol users - $+0.67 \mathrm{mmol} / \mathrm{l}(\mathrm{P}<0.001)$, in the sober respondents $-+0.28 \mathrm{mmol} / \mathrm{l}$ $(\mathrm{P}<0.02)$. Further dynamics of glycemic level in the remaining 26 participants (one participant declined from continuing the experiment as a result of fatigue after $3 \mathrm{hrs}$ from the start), that continued the experiment was different from that in the first two hours of work. 
Increase in the level of glycemia after $4 \mathrm{hrs}$ of mental work was $+0.35 \mathrm{mmol} / \mathrm{l}(\mathrm{P}<0.05)$ compared to the initial level; by $0.05 \mathrm{mmol} / \mathrm{l}$ less compared to the level after $2 \mathrm{hrs}$ (table 2). After 6hrs of mental work average glycemic level increased slightly, but was not different from the level at the first blood sampling, although was less compared to the level after 2 and $4 \mathrm{hrs}$ of work (table 2). This suggests that the process of using glucose is more pronounced than the process of its formation (after 4 hrs of work) and entrance of glucose into blood: the exhaustion of reserves and stimulation of gluconeogenesis for the maintenance of proper level of blood glucose, to providing the energy requirements of actively working cells and organs. Cessation of increase of glycemic level after $4 \mathrm{hrs}$ of work among the majority of respondents and its normalization after 6hrs of mental activities was because of the differences in the dynamics of this important parameter in all participants (figure 2; table 2).

In all non-alcohol users, in all phases of the experiment, there was increase in the glycemic level. The average increase of the glycemic level in relation to the initial level was +0.67 $\mathrm{mmol} / 1(\mathrm{P}<0.05)$ after $2 \mathrm{hrs},+1.16 \mathrm{mmol} / \mathrm{l}(\mathrm{P}<0.001)$ after 4hrs, and $+1.54 \mathrm{mmol} / \mathrm{l}(\mathrm{P}<0.001)$ after 6hrs. Positive dynamics of increase in the glycemic level among the non-alcohol users in a condition of active use of glucose by the brain imply a high reserve of gluconeogenesis amongst them and its intense stimulation in a condition of long-term mental activities. If one should bring into mind the fact that [in condition of catabolism, gluconeogenesis determines the quantity of glucose that enters the blood (De Galan et al., 2006; Krebs 1968), and that glucose use by the brain during mental activities increases at least by $12 \%$ (Madsen et al., 1995; Di Nuzzo et al., 2009), that increase in glycemic level after 6hrs of work among the non-alcohol users was $36.3 \%$ /table $2 /$ ], then calculation of shows increase in the activity of gluconeogenesis by approximately 1.53 times in relation to the initial level.

Amongst the group 2 students, dynamics of glycemia after 4 and 6 hrs of mental activities were significantly different from that of the non-alcohol users (table 2). So, increase in blood glucose in the sober respondents after $2 \mathrm{hrs}$ of mental work $(+0.28 \mathrm{mmol} / \mathrm{l} / \mathrm{P}<0.02 /)$ was replaced by a decrease after $4 \mathrm{hrs}$ of mental work and the development of hypoglycemia (3.99 mmol/1 $/ \mathrm{P}<0.05 /$ ) for capillary blood (table 2) after 6hrs of mental activities. Three students had neuroglycopenia at the end of the experiment, because their blood glucose level was less than $3.0 \mathrm{mmol} / \mathrm{l}$. This is a confirmation that the reserve of gluconeogenesis in sober individuals is significantly decreased compared to the non-alcohol users.

Pearson linear correlation analysis showed the presence of significant (linear, positive) linkages between the glycemic level and effectiveness of cognitive function in all tests after 4 and 6 hrs of mental activities (table 3). In addition, after 4 and 6 hrs of work, there was a significant negative correlation between blood glucose and number of error commission in the test "Correction Probe" (table 3). Calculation of the coefficient of determination $\left(\mathrm{r}^{2}\right)$ shows that the proportion by contribution of glycemic level and effectiveness of cognitive functions in all tests were $11.8 \%(\mathrm{P}<0.05)$ after $4 \mathrm{hrs}$ and $15.6 \%(\mathrm{P}<0.05)$ after 6 hrs of work. The calculated percentage of the effect of blood glucose on the parameters of mental performance clearly does not agree with literature data (Madsen et al., 1995; Di Nuzzo et al., 2009 ) on the positive effect of glycemia as energy source for neurons (on the average 35\%). One can assume that the effect of glycemic control on cognitive functions carry a linear 
character, not a curvilinear one, especially if we consider the fact that indirect source of glucose to the majority of neurons is through glial cells.

\subsection{Effect of glycemic control on error commission}

The conducted calculation of the coefficient of correlational relationship of Pearson " $\eta$ " for the analysis of the degree of curvilinear linkage showed the presence of one-sided effect (with average strength) of glycemia on effectiveness of cognitive function and number of error commission in the test "Correction Probe" for the analysis of mental performance and fatigue in the participants (table 3). Calculations of the coefficient of determination $\eta^{2}$, or $r^{2}$ confirms with sufficient evidence of a direct role of glycemic level ( $26.0 \%$ on fasting at rest; $30.0-36.7 \%$ on fasting during mental work) amongst all factors, contributing to mental performance and the state of cognitive functions. The proportion by contribution of glycemia $(26.0-36.7 \% / \mathrm{P}<0.01 /)$ in the provision of brain functions (mental performance of a person) closely agree with the value (35.0 \%) (Madsen et al., 1995; Di Nuzzo et al., 2009) for the provision of energy for neurons in different conditions. Therefore, sufficient concentration of blood glucose is one of the major factors of high mental performance and high state of cognitive processes.

\begin{tabular}{|c|c|c|c|c|}
\hline \multirow{3}{*}{$\begin{array}{c}\text { Type of correlation, } \\
\text { pair of correlating } \\
\text { parameters }\end{array}$} & \multicolumn{4}{|c|}{ Values of correlation coefficients } \\
\hline & Before work & & During work & \\
\hline & Initial $\left(1^{\text {st}}\right)$ & After 2hrs (2nd) & After 4hrs (3rd) & After 6hrs $\left(4^{\text {th }}\right)$ \\
\hline Participants & $\mathrm{n}=27$ & $\mathrm{n}=27$ & $\mathrm{n}=26$ & $\mathrm{n}=26$ \\
\hline $\begin{array}{c}\text { rearsonGl- NO in the } \\
\text { test "CP", }\end{array}$ & $\begin{array}{l}r=-0.01 \\
P=0.994\end{array}$ & $\begin{array}{l}\mathrm{r}=-0.165 \\
\mathrm{P}=0.206\end{array}$ & $\begin{array}{c}\mathrm{r}=-0.364 \\
\mathrm{P}=0.034\end{array}$ & $\begin{array}{c}\mathrm{r}=-0.398 \\
\mathrm{P}=0.022\end{array}$ \\
\hline $\begin{array}{c}\text { pearson } \mathrm{Gl}-\mathrm{NO} \text { in } \\
\text { the test "CP", } \\
\text { Effect of } \mathrm{Gl} \text { on } \mathrm{NO}\end{array}$ & \begin{tabular}{|c|}
$\eta=0.510^{\mathbf{D}}$ \\
$P<0.01$ \\
$\eta^{2} \cdot 100 \%=26.0 \%^{\text {a }}$
\end{tabular} & 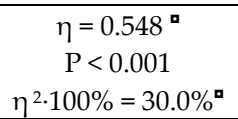 & $\begin{array}{c}\eta=0.606^{\mathbf{D}} \\
P<0.001 \\
\eta^{2 \cdot 100 \%=36.7 \%}{ }^{\text {व }}\end{array}$ & 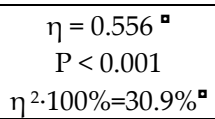 \\
\hline
\end{tabular}

Note: Gl - glucose (concentration of glucose in capillary blood); $\mathrm{NO}$ - number of errors; test "CP" - test "Correction Probe"; r - linear correlation coefficient of Pearson; $\eta$-curvilinear correlation coefficient of Pearson; of linkage between the parameters with respect to " $r$ " linear correlation coefficient of Pearson set at $P \leq 0,05 ;{ }^{\circ}-$ significance of one-sided effect of glucose on number of error committed by the participants on the test "CP", in relation to " $\eta$ " curvilinear correlation coefficient of Pearson set at $\mathrm{P} \leq 0,05$. Proportion of interrelationship of the analyzed parameters were calculated based on the coefficient of determination $\left(\mathrm{r}^{2}\right)$ [see Welcome et al., 2011]. Tests were conducted together with the blood sampling of glucose in each phase of the experiment.

Table 3. Effect of glycemia on the parameters of cognitive functions and the functional state of the participants

The hypoglycemic effect of acute alcohol administration has been known for decades. As reported by Hans Krebs and associates, alcohol reduces the activeness of gluconeogenetic enzymes (Krebs 1968; Krebs et al., 1969). We had reported that the negative effect of chronic (episodic) alcohol use on gluconeogenesis maybe long-term (might last even for 10-30 days after alcohol use), and might be noticed under long-term mental work (4-6 hrs), especially in task requiring high cognitive control (Welcome et al., 2011; Fig. 2). 
The fact that decrease in neuronal gluconeogenesis (leading to $\downarrow$ blood-brain glucose level) caused by alcohol consumption in a cognitive task might affect the activities of the EMPS by increase in the number of error commission is evident in the hypothalamic control of blood and brain glucose levels (Welcome et al., 2010; Volkow et al., 2006). The blood glucose level increases with increase in dopamine level on fasting (Umhau et al., 2003). Effect of glucose on dopamine is realized through the activities of GLUT- 2 receptor located in hypothalamic neurons (Umhau et al., 2003; Williams et al., 2007; Pizzagalli 2003).

The basal ganglia and hypothalamus are actively engaged with the brain regions of cognitive control to adequately carryout a task to meet set aims. To meet the set aims, one of the control mechanisms is to avoid error commission. However, in rare circumstances error commission can be an adaptive mechanism for safety, and accommodation, and may result from neuronal selectivity pattern (Gehring et al., 1993; Hester et al., 2005; Bello \& Hajnal 2006). The increased error commission associated with alcohol consumption is related to decrease in dopaminergic functions (Nieuwenhuis et al., 2002; Holroyd \& Yeung 2003), which is caused by decreased competence of glucose allostasis regulation (Welcome et al., 2010, 2011).

It is possible to assume that functional hypoglycemia among sober individuals (within a period of 30 days after alcohol use) in a condition of mental activities may lead to disorders in dopamine metabolism and subsequently cause disruption of EMPS through increase in erroneous actions.

According to the ARGD-EMPS hypothesis, the disruption of the EMPS is related to the competency of glucose allostasis regulation, which in turn may determine the dopamine level as a major component of the EMPS (Welcome et al., 2010).

Blood and brain glucose levels play a vital role in error commission, and are related to error commission, monitoring and processing through the modulation of the activity of the dopaminergic system (Volkow et al., 2006; Umhau et al., 2003; Williams et al., 2007; Pizzagalli 2003). In fact, decreased glucose metabolism in ACC closely correlates with the results of neurophysiological tests (Pizzagalli et al., 2003).

The ARGD-EMPS hypothesis was put forward based on recent evidences, which suggest that alcohol's action on error monitoring ad processing is related to its action on glucose homeostasis regulation, especially in tasks requiring high cognitive control (Welcome et al., 2010). In addition, the number of errors committed in an experiment is inversely correlated with the glycemic levels, especially among alcohol users (Welcome et al., 2010, 2011; Fig. 2). In addition, correlation analysis between academic performance and the number of errors committed by alcohol users in high-level cognitive task is also a confirmation (Welcome et al., 2010, 2011; Fig. 2).

\section{Conclusion}

The basal ganglia represent a crucial relay station for error monitoring and processing between several brain regions including emotional and cognitive brain areas. The disruption 
of error monitoring and processing by alcohol might not follow an indirect pathway only, but also a direct one. Indirect effect of alcohol may be possible through the processing capacity of the basal ganglia by affecting other brain areas connected to the basal ganglia; action of alcohol metabolites (acetaldehyde; acetate; protein-, lipid-, enzyme-, and DNAadducts of alcohol) on the processing of information in the basal ganglia and/or associated brain pathways; and its action on neuromediators that modulate the processing of information in the basal ganglia and/or associated brain pathways. The direct effect might be attained if alcohol reach the basal ganglia and causes disruption of cellular processes including information processing. The effect is a change in effectiveness of cognitive functions, error commission in the macro world. The effect of alcohol on the basal ganglia's error monitoring and processing capacity might last for several days after alcohol use (up to 30 days). This effect might be noted, especially under long-term intensive mental activities requiring high cognitive control, when the glucose reserves in the body cannot support long-term actively working neurons, and this may lead to disorders in dopamine metabolism and subsequently cause disruption of EMPS through decrease in effectiveness of cognitive functions, increase in erroneous actions.

\section{Future research}

Future research will examine both the electrophysiological (ECG, ERN etc.) and radiological (PET, etc) parameters of dose-time response effect of alcohol in details. In the initial stage, animal models will be used to research the basis and to test how alcohol affect specific neuron or group of neurons in basal ganglia-thalamo-cortico-limbic pathways. Other pathways with indirect connections to the basal ganglia whose dysfunctions may necessary lead to a decrease in basal ganglia function will also be examined. A knockout of the alcohol pocket-receptor might also reveal useful information about the indirect effect of alcohol on error monitoring and processing.

\section{Author details}

M.O. Welcome and V.A. Pereverzev

Belarusian State Medical University, Minsk, Belarus

\section{References}

Aarts K, Pourtois G. Anxiety not only increases, but also alters early error-monitoring functions. Cogn Affect Behav Neurosci. 2010;10 (4): 479-492.

Amodio DM, Kubota JT, Harmon-Jones E, Devine PG. Alternative mechanisms for regulating racial responses according to internal vs external cues. SCAN. 2006; 1: 26-36.

Aparicio P, Diedrichsen J, Ivry RB. Effects of focal basal ganglia lesions on timing and force control. Brain Cognition. 2005; 58: 62-74.

Bello NT, Hajnal A. Alterations in blood glucose levels under hyperinsulinemia affect accumbens dopamine. Physiol Behav 2006; 88: 138-145. 
Berry EL, Nicolson RI, Foster JK, Behrmann M, Sagar HJ. Slowing of Reaction Time in Parkinson's Disease: The Involvement of the Frontal Lobes. Neuropsychologia. 1999; 37: 676-684.

Beste C, Saft C, Andrich J, Gold R, Falkenstein M. Error Processing in Huntington's Disease. PLOS ONE. 2006; 1(1): e86.

Beste C, Saft C, Andrich J, Gold R, Falkenstein M. Stimulus-Response Compatibility in Huntington's Disease: A Cognitive-Neurophysiological Analysis. J Neurophysiol. 2008; 99:1213-1223.

Beste C, Saft C, Andrich J, Mu“ ller T, Gold R, Falkenstein M. Time Processing in Huntington's Disease: A Group-Control Study. PLoS ONE. 2007; 2 (12):e1263.

Beste C, Willemsen R, Saft C, Falkenstein M. Error processing in normal aging and in basal ganglia disorders. Neuroscience. 2009; 159: 143-149.

Bocquillon P, Bourriez J-L, Palmero-Soler E, Deste'e A, Defebvre L, Derambure P, Dujardin K. Role of Basal Ganglia Circuits in Resisting Interference by Distracters: A swLORETA Study. PLoS ONE. 2012; 7 (3): e34239.

Botvinick MM, Braver TS, Barch DM, Carter CS, Cohen JD. Conflict monitoring and cognitive control. Psychol Rev. 2001; 108 (3): 624-652.

Botvinick MM, Cohen JD, Carter CS. Conflict monitoring and anterior cingulate cortex: an update. Trends Cogn Sci. 2004; 8 (12): 539-546.

Buhler R, Pestalozzi D, Hess M, von Wartburg J.-P. Immunohistochemical Localization of Alcohol Dehydrogenase in Human Kidney, Endocrine Organs and Brain. Pharmacol Biochem Behav. 1983; 18 (1): 55-59.

Calhoun VD, Pekar JJ, Pearlson GD. Alcohol intoxication effects on simulated driving: exploring alcohol-dose effects on brain activation using functional MRI. Neuropsychopharmacology 2004; 29: 2097-2107.

Carter CS, Braver TS, Barch DM, Botvinick MM, Noll D, Cohen JD. Anterior cingulate cortex, error detection, and the online monitoring of performance. Science 1998; 280: 747749 .

Charlesworth JD, Warren TL, Brainard MS. Covert skill learning in a cortical-basal ganglia circuit. Nature. 2012; 486: 251-255.

De Galan BE, Schouwenberg BJ, Tack CJ, Smits P. Pathophysiology and management of recurrent hypoglycaemia and hypoglycaemia unawareness in diabetes. Neth J Med 2006; 64: 269-279.

Deitrich, Zimatkin S, Pronko S. Oxidation of Ethanol in the Brain and Its Consequences. Alcohol Res Health. 2006; 29 (4): 266-273.

Del Rio Carmen M, Gonzalez-Luque JC, Alvarez FJ. Alcohol Alcohol. 2001; 36 (3): 256-261.

Dhar M, Wiersema JR, Pourtois G. Cascade of Neural Events Leading from Error Commission to Subsequent Awareness Revealed Using EEG Source Imaging. PLoS ONE. 2011; 6 (5): e19578.

Di Nuzzo M, Giove F, Bruno Maraviglia. A biochemical framework for modeling the functional metabolism of the human brain. Biophys BioEngin Letters 2009; 2 (2): 1-26. 
Easdon C, Izenberg A, Armilio ML, Yu H, Alain C. Alcohol consumption impairs stimulusand error-related processing during a Go/No-Go Task. Brain Res Cogn Brain Res. 2005; 25: 873-883.

Endrass T, Klawohn J, Preuss J, Kathmann N. Temporospatial dissociation of Pesubcomponentsforperceivedandunperceivederrors. Front Hum Neurosci. 2012; 6 (Article178): 1-10.

Falkenstein M, Hohnsbein J, Hoormann J. Event-related potential correlates of errors in reaction tasks. In: G Karmos, M Molnar, V Csepe, I Czigler, JE Desmedt, eds. Perspectives of Event-related Potentials Research. Amsterdam: Elsevier. 1995; 287-296.

Falkenstein M, Hoormann J, Christ S, Hohnsbein J. ERP components on reaction errors and their functional significance: a tutorial. Biol Psychol. 2000; 51 (2-3): 87-107.

Fein G, Chang M. Smaller feedback ERN amplitudes during the BART are associated with a greater family history density of alcohol problems in treatment-naïve alcoholics. Drug Alcohol Depend. 2008; 92 (1-3): 141-148.

Franken IHA, van Strien JW, Kuijpers I. Evidence for a deficit in the salience attribution to errors in smokers. Drug Alcohol Depend. 2010; 106 (2-3): 181-185.

Garavan H, Ross TJ, Murphy K, Roche RA, Stein EA. Dissociable executive functions in the dynamic control of behavior: inhibition, error detection, and correction. Neurolmage. 2002; 17: 1820-1829.

Garavan H, Ross TJ, Murphy K, Roche RA, Stein EA. Dissociable executive functions in the dynamic control of behavior: inhibition, error detection, and correction. Neuroimage. 2002;17 (4):1820-1829.

Gehring WJ, Fencsik DE. Functions of the medial frontal cortex in the processing of conflict and errors. J Neurosci. 2001; 21: 9430-9437.

Gehring WJ, Goss B, Coles M, Meyer D, Donchin E. A neural system for error detection and compensation. Psychol Sci. 1993; 4: 385-390.

Giesbrecht T, Geraerts E, Merckelbach H. Dissociation, memory commission errors, and heightened autonomic reactivity. Psychiatr Res. 2007; 150: 277-285.

Goldstein RZ, Tomasi D, Rajaram S, et al. Role of anterior cingulate and medial orbitofrontal cortex in processing drug cues in cocaine addiction. Neuroscience. 2007; 144: 1153-1159.

Goodlett CR, Horn KH. Mechanism of Alcohol Induced Damage to the Developing Nervous System. Alcohol Res Health 2001; 25 (3): 175-184.

Haight JS, Keatinge WR. Failure of thermoregulation in the cold during hypoglycaemia induced by exercise and ethanol. J Physiol 1973; 229: 87-97.

Haltia LT, Rinne JO, Merisaari H, Maguire RP, Savontaus E, Helin S, Någren K, et al. Effects of intravenous glucose on dopaminergic function in the human brain in vivo. Synapse 2007; 61: $748-756$.

Hester R, Foxe JJ, Molholm S, Shpaner M, Garavan H. Neural mechanisms involved in error processing: a comparison of errors made with and without awareness. NeuroImage. 2005; 27: 602-608. 
Holroyd CB, Coles MGH. The neural basis of human error processing: reinforcement learning, dopamine, and the error-related negativity. Psychol Rev. 2002; 109: 679-709.

Holroyd CB, Praamstra P, Plat E, Coles MGH. Spared error-related potentials in mild to moderate Parkinson's disease. Neuropsychologia. 2002; 1419: 1-9.

Holroyd CB, Praamstra P, Plat E, Coles MGH. Spared error-related potentials in mild to moderate Parkinson's disease. Neuropsychologia. 2002; 40: 2116-2124.

Holroyd CB, Yeung N. Alcohol and error processing. Trends Neurosci 2003; 26: 402- 404.

Hurst JW. Cognitive Errors (Can They Be Prevented?). Am J Cardiol. 2008; 101 (10): 15131517.

Jin DZ, Fujii N, Graybiel AM. Neural representation of time in cortico-basal ganglia circuits. PNAS. 2009; 106 (45): 19156-19161.

Krebs HA. The effects of ethanol on the metabolic activities of the liver. Adv Enzyme Regul 1968; 6: 467-480.

Krebs, HA, Freedland RA, Hems R, Stubbs M. Inhibition of hepatic gluconeogenesis by ethanol. Biochem J 1969; 112:117-124.

Krigolson OE, Holroyd CB. Hierarchical error processing: different errors, different systems. Brain Res. 2007; 1155: 70-80.

Madsen PL, Hasselbalch SG, Hageman LP, Olsen KS, Bulow J, Holm S, Wildschioedtz G, Paulson OB, Lassen NA. Persistent resetting of the cerebral oxygen/glucose uptake ratio by brain activation: evidence obtained with the KetySchmidt technique. J Cereb Blood Flow Metabol 1995; 15: 485-491.

Marco-Pallarés J, Camara E, Münte TF, Rodríguez-Fornells A. Neural mechanisms underlying adaptive actions after slips. J Cogn Neurosci. 2008; 20 (9): 1595-610.

Mathalon DH, Whitfield SL, Ford JM. Anatomy of an error: ERP and fMRI, Biol Psychol. 2003; 64: 119-141.

Mitler MM, Carskadon MA, Czeisler CA, Dement WC, Dinges DF, Graeber RC. Catastrophes, Sleep, and Public Policy: Consensus Report. Sleep. 1988; 11(1): 100-109.

Montague PR, Dayan P, Sejnowsk TJ. A framework for mesencephalic dopamine systems based on predictive Hebbian learning. J Neurosci 1996; 76: 1936-1947.

Münte TF, Heldmann M, Hinrichs $\mathrm{H}$, et al. Nucleus accumbens is involved in human action monitoring: evidence from invasive electrophysiological recordings. Hum Neurosci. 2008; 1 (11): 1-6.

Nick Y, Botvinick MM, Cohen JD. The neural basis of error detection: Conflict monitoring and the error-related negativity. Psychol Rev. 2004; 111 (4): 931-959.

Nieuwenhuis S, Holroyd CB, Mol N, Coles MG. Reinforcement related brain potentials from medial frontal cortex: origins and functional significance. Neurosci Biobehav Rev 2004; 28: 441-448.

Nieuwenhuis S, Ridderinkhof KR, Talsma D, et al. A computational account of altered error processing in older age: dopamine and the error-related negativity. Cogn Affect Behav Neurosci. 2002; 2: 19-36. 
Nieuwenhuis S, Yeung N, van den Wildenberg W, Ridderinkhof KR. Electrophysiological correlates of anterior cingulate function in a Go/NoGo task: Effects of response conflict and trial-type frequency. Cogn Affect Behav Neurosci. 2003; 3: 17-26.

Olvet DM, Hajcak G. The error-related negativity (ERN) and psychopathology: Toward an endophenotype. Clin Psychol Rev. 2008: 28 (8): 1343-1354.

Pailing PE, Segalowitz SJ. The error-related negativity as a state and trait measure: Motivation, personality, and ERPs in response to errors. Psychophysiology. 2004; 41(1): 84-84.

Pizzagalli DA, Oakes TR, Davidson RJ. Coupling of theta activity and glucose metabolism in the human rostral anterior cingulate cortex: an EEG/PET study of normal and depressed subjects. Psychophysiology. 2003; 40: 939 -949.

Pontifex MB, Scudder MR, Brown ML, O'Leary KC, Wu C-T, Themanson JR, Hillman CH. On the number of trials necessary for stabilization of error-related brain activity across the life span. Psychophysiology. 2010; 47: 767-773.

Quertemont E. Genetic polymorphism in ethanol metabolism: acetaldehyde contribution to alcohol abuse and alcoholism. Mol Psychiatry. 2004; 9: 570-581.

Ridderinkhof KR, de Vlugt Y, Bramlage A, Spaan M, Elton M, Snel J, Band GP. Alcohol consumption impairs detection of performance errors in mediofrontal cortex. Science 2002; 298: 2209-2211.

Ridderinkhof KR, Nieuwenhuis S, Bashore TR. Errors are foreshadowed in brain potentials associated with action monitoring in cingulate cortex. Neurosci Lett. 2003; 348: 1-4.

S Gauggel, M Rieger, T-A Feghoff. Inhibition of ongoing responses in patients with Parkinson's disease. J Neurol Neurosurg Psychiatry. 2004; 75: 539-544.

Salvador M-A, Alfredo S-M. Cellular and Mitochondrial Effects of Alcohol Consumption. Int J Environ Res Pub Health. 2010; 7: 4281-4304.

Stevens MC, Kiehl KA, Pearlson GD, Calhoun VD. Brain Network Dynamics During Error Commission. Hum Brain Mapp. 2009; 30 (1): 24-37.

Suri R, Schultz W. A neural network with dopamine-like reinforcement signal that learns a spatial delayed response task. Neuroscience. 1999; 91: 871-890.

Umhau JC, Petrulis SG, Diaz R, Rawlings R, George DT. Blood glucose is correlated with cerebrospinal fluid neurotransmitter metabolites. Neuroendocrinology 2003; 78: 339-343.

van Veen V, Carter CS. Error detection, correction, and prevention in the brain: a brief review of data and theories. Clin EEG Neurosci. 2006; 37 (4): 330-335.

Vocat R, Pourtois G, Vuilleumier P. Unavoidable errors: a spatio-temporal analysis of timecourse and neural sources of evoked potentials associated with error processing in a speeded task. Neuropsychologia. 2008; 46 (10): 2545-55.

Volkow ND, Wang G-J, Franceschi D, et al. Low doses of alcohol substantially decrease glucose metabolism in the human brain. Neurolmage. 2006; 29: 295 - 301.

Welcome MO, Pereverzeva EV, Pereverzev VA. Long-term disorders of cognitive functions in sober people who episodically use alcohol, role of functional hypoglycemia and insufficiency of gluconeogenesis. Bull Smolensk Med Acad 2011; № 3: 2-20. 
Welcome MO, Razvodovsky YE, Pereverzeva EV, Pereverzev VA. The effect of blood glucose concentration on the error monitoring and processing system in alcohol users during intensive mental activities. Port Harcourt Med J. 2011; 5 (3) 293-306.

Welcome MO, Razvodovsky YE, Pereverzeva EV, Pereverzev VA. The error monitoring and processing system in alcohol use. IJCRIMPH. 2010; 2 (10): 318-336.

Wick MJ, Mihic SJ, Ueno S, Mascia MP, Trudell JR, Brozowski SJ, Ye Q, Harrison NL, Harris RA. Mutations of g-aminobutyric acid and glycine receptors change alcohol cutoff: Evidence for an alcohol receptor? Proc Natl Acad Sci USA. 1998; 95: 6504-6509.

Williams JM, Owens WA, Turner GH, Saunders C, Dipace C, Blakely RD, France CP, et al. Hypoinsulinemia regulates amphetamine-induced reverse transport of dopamine. PLoS Biol. 2007; 5: e274.

Schulte T, Müller-Oehring EM, Strasburger H, Warzel H, Sabel BA. Acute effects of alcohol on divided and covert attention in men. Psychopharmacology. 2001; 154 (1): 61-69.

Ochoa G. Error Thresholds in Genetic Algorithms. J Evolut Comput. 2006; 14 (2): 157 - 182.

Takeuchi N, Poorthuis PH, Hogeweg P. Phenotypic error threshold; additivity and epistasis in RNA evolution. BMC Evolut Biol. 2005; 5:9. doi:10.1186/1471-2148-5-9.

Cohen SM, Ellwein LB. Genetic Errors, Cell Proliferation, and Carcinogenesis. Cancer Res. 1991; 51: 6493-6505. 